\title{
Diálogos entre Geografia e Literatura nas salas de aula da Educaçáo Básica
}

Helaine da Costa Braga*

\section{Resumo}

Este artigo apresenta reflexóes sobre os elos entre a Geografia e a Literatura e propóe a inter-relaçáo das duas linguagens como modo de enriquecer as leituras do espaço geográfico nas salas de aula da Educaçáo Básica. É possível encontrar, nas diversas modalidades literárias - poemas, romances, crônicas, contos -, representaçóes do mundo vivido. Por meio de narrativas do cotidiano, simbolizaçáo da cultura dos lugares e paisagens e alusão a elementos da natureza, a linguagem subjetiva da Literatura pode aguçar a sensibilidade e o imaginário dos alunos e potencializar o conhecimento geográfico. A concepçáo de que a Literatura dialoga bem com a Geografia é o viés para que os professores de Geografia Escolar desenvolvam propostas interdisciplinares. Propostas que, ao buscar contextualizar e significar os conhecimentos da Geografia Escolar, contemplem textos literários nos quais os conteúdos e cenários tenham relaçáo com o mundo vivido dos alunos. Nesta perspectiva, desvelar diferentes aspectos das sociedades, das paisagens e dos modos de existir humano em obras literárias pode trazer importantes contribuiçôes para o ensino-aprendizado da Geografia Escolar.

Palavras-chave: geografia, literatura, interdisciplinaridade, educação básica.

\section{Dialogues between Geography and Literature in Basic Education classrooms}

\section{Abstract}

This article presents reflections on the links between Geography and Literature and suggests the interrelationship of the two languages as a way of enriching the readings of geographical space in the classrooms of basic education. It can be found in various literary forms poems, novels, essays, short stories -, representations of the lived world. Through everyday narratives, cultural symbolism of the places and their landscapes, alluding to the elements, the subjective language of literature can sharpen the sensitivity and imagination of students and enhance the geographical knowledge. The conception that Literature dialogues well with the Geography is the way in which School Geography teachers can develop interdisciplinary proposals. These proposals should seek to contextualize and mean the knowledge of School Geography, contemplate literary texts in which the contents and scenarios are related to the

* Graduada em Geografia pela Universidade Federal de Goiás. Mestre em Geografia pela Universidade Federal de Goiás. Professora de Geografia da Secretaria Municipal de Educaçáo de Goiânia e da Secretaria de Estado de Educaçáo, Cultura e Esporte de Goiás. E-mail: helainecostabraga@gmail. com. 
world of the students. In this perspective, revealing different aspects of societies, landscapes and ways of mankind's human existence in literary works can bring important contributions to teaching-learning of School Geography.

Keywords: geography, literature, interdisciplinary, basic education.

\section{Introduçáo}

No leque de disciplinas que compóem o currículo escolar, a Geografia situa-se como uma importante linguagem para a compreensão do mundo. Ao lado das demais áreas do conhecimento, ela oferece um aporte teórico e uma proposta pedagógica ricos em conceitos e métodos que têm o papel de habilitar os alunos na leitura e na intervençáo da realidade. Aos professores, no seu ofício de mediar o processo de ensino e aprendizagem, cabe o exercício de encontrar práticas que possibilitem a construçáo e a apropriaçáo de conhecimentos geográficos.

Em Geografia, os conceitos e métodos intencionam explicar a realidade espacial do mundo. Nesta perspectiva, há uma procura constante dos professores por formas de ensino que favoreçam a interaçáo dos alunos com o objeto de estudos, ou seja, com o espaço geográfico.

Dentre as formas de ensinar Geografia, são crescentes aquelas que buscam valorizar a subjetividade do espaço. Essa valorizaçáo significa, por exemplo, levar em conta, nos estudos das paisagens de diferentes lugares, territórios e regióes, as identidades, as afetividades, as crenças e os desejos das pessoas.

A perspectiva de ensino que enfatiza as subjetividades dos sujeitos na construção do espaço tem respaldo na abordagem cultural da Geografia e faz parte de uma tendência de pluralidade desta disciplina. Consideramos essa abordagem apropriada para refletir sobre o mundo atual.

O enfoque plural da Geografia favorece sua relaçáo com outras áreas do conhecimento e motiva a realizaçáo de projetos interdisciplinares no ambiente escolar. Uma proposta interdisciplinar interessante, que pode conduzir os alunos a buscar com mais curiosidade o entendimento da espacialidade humana, é a que aposta em diálogos entre a Geografia e a Literatura.

Neste texto, nossa intenção é ampliar o entendimento de como a Literatura pode contribuir para o ensino da Geografia, uma vez que a composição literária, os cenários literários, os enredos e as personagens são criaçóes que, não raras vezes, têm identificaçôes com lugares e pessoas na realidade da sua existência. 


\section{A dimensão sensível de percepçáo do mundo}

De acordo com os Parâmetros Curriculares Nacionais (PCN), a dimensáo sensível de percepçáo do mundo aventa uma possibilidade de conhecer o espaço geográfico pela subjetividade do imaginário. $\mathrm{O}$ texto do documento esclarece que

falar do imaginário em Geografia é procurar compreender os espaços subjetivos, os mapas mentais que se constroem para orientar as pessoas no mundo. Quando se pensa sobre o mundo rural e urbano, um bairro ou mesmo um país, se constroem com o imaginário esses espaços. $\mathrm{O}$ imaginário náo deve ser aqui compreendido como o mundo do devaneio, mas o das representaçóes. Mesmo existindo somente na imaginaçáo, elas adquirem uma grande autonomia e participam nas decisóes tomadas no cotidiano. Nesse sentido, acreditamos que trabalhar com o imaginário do aluno no estudo do espaço é facilitar a interlocuçáo com ele e compreender o significado que as diferentes paisagens, lugares e coisas têm para ele. Tudo isso significa dizer, valorizar os fatores culturais da vida cotidiana permitindo compreender ao mesmo tempo a singularidade e a pluralidade dos lugares no mundo. (BRASIL, 1998, p. 23).

Como se vê, as recomendaçôes curriculares reforçam a premissa de que mundo vivido também é mundo imaginado. Autores como Durand (1993) e Maffesoli (2001) argumentam sobre essa premissa, concordando que o real é a matéria-prima do imaginário. Neste sentido, as representaçóes, segundo Kozel (2006), exercem um papel relevante na apropriaçáo e na construçáo de conhecimentos geográficos. Ao permitir que os alunos recriem na mente as coisas do mundo vivido (e a estas coisas atribuam significados), elas, as representaçóes, podem ser uma ponte para alcançar a realidade objetiva. Pois, de acordo com Cavalcanti (2005, p. 36):

As representaçóes sociais estão no nível do conhecimento vivido e sentido, que contém elementos de um conceito já potencialmente existente nos alunos, podendo, assim, ser tomado como parâmetro de uma aprendizagem significativa.

A possibilidade de compreender o mundo vivido também pela subjetividade do imaginário fora negligenciada pelas geografias tradicional, quantitativa e marxista, conforme lembram Cavalcanti (2005), Straforini (2004), Pontuschka (2007) e os próprios PCN de Geografia. Em consequência, as 
produçóes didáticas - livros didáticos e paradidáticos, revistas didáticas e outras - influenciadas por essas correntes apresentam uma abordagem insuficiente na sua capacidade de levar os alunos a perceber a complexidade e a pluralidade do espaço, sobretudo nos aspectos culturais.

Atualmente, acadêmicos e professores de Geografia têm conhecimento de uma variedade de opçóes didáticas no seu campo de atuaçáo. Dentre elas, algumas propóem possibilidades para apresentar aos alunos novas abordagens da Geografia. Geralmente, tais abordagens contêm propostas pedagógicas que, além de assumir um compromisso social e político com o estudo do espaço, sugerem que os professores lancem máo de outras linguagens na empreitada de ensinar essa disciplina.

Literatura, músicas, filmes, fotografias e artes plásticas são linguagens que apresentam relaçóes com o aspecto sensorial da aprendizagem. Aliás, a percepçáo sensorial das coisas que existem no mundo possui uma importância especial para os estudos geográficos, no processo de ensino e aprendizagem da Geografia Escolar.

Por exemplo, não sáo raras às vezes em que elegemos as paisagens como ponto de partida para compreender diferentes lugares, territórios e regióes. Nestas situaçóes de ensino e aprendizagem, em que os alunos têm a oportunidade de entender como cada sentido do corpo humano percebe e interage com as diferentes paisagens, nota-se o quanto a noçáo de paisagem adquire mais significado ao ser trabalhada a partir das sensaçóes de ouvir, ver, sentir, falar e mesmo saborear.

Neste sentido, acreditamos que, pelas sensaçóes que a leitura de diferentes gêneros literários pode despertar nos alunos, é provável que fique mais compreensível a eles a ideia do espaço geográfico como construçáo humana que tem como alicerces nâo só a natureza e a economia, mas, também, a cultura a que cada grupo social pertence.

\section{Os elos entre a Geografia e a Literatura}

"jogo da amarelinha

terra e céu

crianças no paraíso"

(BARBOSA, 2011) 
Dependendo da sensibilidade de quem lê, o haicai do poeta mineiro Joaquim Pedro Barbosa chega aos sentidos com tons de pintura e sons de música. A imagem que ele representa parece uma fotografia do lúdico que a lente poética mirou e o artista revelou em forma de verso.

O poema curto, sem título, formado por três versos, expressa o conteúdo estético e subjetivo da Literatura. Ele evidencia uma relaçáo com o belo e com a sensibilidade, ao representar uma brincadeira comum da infância. A Literatura, nos seus diferentes gêneros, entre outras características, possui esta habilidade de falar da realidade com uma liberdade imaginativa capaz de recriar os fatos e emocionar as pessoas. Por se tratar de uma linguagem artística, na qual há espontaneidade de criaçáo, ela é capaz de aguçar a percepção e a curiosidade dos leitores, além de dar liberdade à imaginação.

Ao propor a aproximaçáo da linguagem geográfica com a literária, no processo de ensino e aprendizagem da Geografia Escolar, reconhecemos que existem elos entre as duas e que, por meio desses elos, os alunos podem ampliar seus conhecimentos geográficos e sua visão de mundo.

Uma relaçáo importante da Geografia com a Literatura está associada à ideia defendida por literatos como Candido (1975), Bosi (1986) e Santos (2004), segundo a qual a realidade concreta é o substrato da criaçáo artística. Isso significa dizer que a Literatura, como parte da cultura, é capaz de expressar a espacialidade de uma dada realidade espaço-temporal. Desta forma, situaçóes cotidianas e lugares vividos pelas pessoas encontram correspondência nos textos e cenários literários.

Brosseau (2007) lembra que, já no início da incorporação da Literatura aos estudos geográficos, os geógrafos buscavam nas obras literárias um conhecimento mais aprofundado do espaço vivido. O autor recorre a Tuan (1974) e a Buttimer (1982) para esclarecer que no estudo do espaço vivido

valores, representaçôes, intençóes, subjetividade, identidade, enraizamento, experiência concreta e percepçáo eram noçóes mobilizadas para situar o sujeito no centro das preocupaçóes dos geógrafos em suas reflexôes sobre as relaçôes homem-lugar". (BROSSEAU, 2007, p. 29).

A abordagem do espaço vivido na Geografia valoriza os sujeitos na sua relaçáo com o lugar onde vivem, levando em conta, claro, que este lugar é atravessado pelos acontecimentos do mundo. Uma leitura geográfica de modalidades literárias - poesias, crônicas, contos, romances - pode poten- 
cializar o conhecimento a respeito dos sujeitos e seus espaços de vivência, uma vez que, na Literatura, eles aparecem realçados em seus atributos.

Esse realce acontece porque os autores, na composição e na transmissão de suas obras, lançam mão de recursos próprios do fazer literário, como, por exemplo, a liberdade criativa, a intuiçáo e a sensibilidade para alcançar aquilo que é mais subjetivo nas pessoas e nos lugares.

A Geografia, ao buscar compreender e explicar o mundo, pode tomar emprestada da Literatura a leitura sensível das paisagens culturais - presentes e passadas, próximas e distantes -, das experiências vividas nos lugares e dos sentimentos e modos de ser das pessoas, como forma de chegar mais próximo da subjetividade humana e da diversidade da cultura presentes em diferentes espaços de vivência.

Estudos nessa perspectiva foram desenvolvidos por Wanderley (1998), Monteiro (2002), Olanda e Almeida (2007), Sousa e Chaveiro (2008), Braga e Almeida (2009), Marandola Jr. e Gratáo (2010), revelando aspectos essenciais do espaço rural e do espaço urbano do Brasil.

A Geografia e a Literatura são formas de conhecimento que possuem linguagens distintas e, ao mesmo tempo, complementares. Se, por um lado, a Geografia, pelos conceitos e métodos que lhe são próprios, busca compreender a espacialidade humana, a Literatura, em seu viés mais subjetivo, oferece importantes informaçóes sobre essa espacialidade.

Náo é sem razáo que muitos geógrafos veem na Literatura uma fonte documental, pedagógica, no sentido de que ela guarda em seus escritos a complexidade do existir humano (os modos de ser das pessoas, a organizaçáo socioespacial), bem como paisagens de períodos históricos específicos. Em se tratando da realidade presente, que pode ser observada diretamente pelo professor-pesquisador, a Literatura exerce o papel de vigorar o olhar geográfico sobre o espaço, pois ela é campo fértil das representaçóes.

O principal enlace da Geografia com a Literatura está no conteúdo humano que elas investigam. A partir deste pressuposto, nas aulas de Geografia na Educaçáo Básica, seja no Ensino Fundamental ou no Médio, nós, professores, podemos encontrar novas possibilidades de conjugar o saber geográfico com o literário.

Os PCN propóem que, nas aulas de Geografia, os alunos da Educação Básica conheçam o espaço, percebam-se nele e tenham mais clareza, enquanto integrantes de um grupo social, das relaçóes existentes entre sociedade e natureza, sociedade e espaço, espaço mundial e lugar de vivência. 
Também de acordo com os PCN, cabe à Literatura ensinada na Educaçáo Básica, entre outros objetivos, levar os alunos a desenvolver a sensibilidade, a capacidade argumentativa, a capacidade crítica, o senso estético, a linguagem e a comunicação. Desta forma, podemos observar, pelas proposiçóes dos PCN, que os objetivos da Literatura se relacionam com os objetivos gerais de uma Geografia comprometida com a formaçáo integral dos alunos.

Kaercher (2001), Cavalcanti (2005) e Castrogiovanni (2006), estudiosos da Geografia Escolar, destacam que, além do objetivo primordial de levar os alunos a desenvolver uma consciência espacial da realidade, há outras habilidades que se esperam do ensino de Geografia. Tais habilidades têm a ver com uma formaçáo mais ampla, que leva em conta as dimensóes física, afetiva, social, moral e estética.

É neste sentido que consideramos apropriada uma abordagem interdisciplinar entre Geografia e Literatura. Uma abordagem que, além de favorecer a compreensão do espaço geográfico, tenha como alvo o desenvolvimento das dimensóes integralizadas da aprendizagem.

\section{Perspectivas do encontro da Geografia com a Literatura}

\section{O bicho}

"Vi ontem um bicho

$\mathrm{Na}$ imundície do pátio

Catando comida entre os detritos.

Quando achava alguma coisa,

Não examinava nem cheirava:

Engolia com voracidade.

O bicho náo era um cão,

Náo era um gato,

Náo era um rato.

O bicho, meu Deus, era um homem."

(BANDEIRA, 1993)

O poema de Manuel Bandeira é um testemunho poético da injustiça social observada em paisagens urbanas. A forma como ele representa a 
condição humana evidencia o quanto a linguagem subjetiva da Literatura pode potencializar o olhar geográfico sobre a realidade. Noutras palavras, podemos enfatizar: o bicho de Manuel Bandeira humaniza o olhar sobre o mundo vivido.

A Poesia é um gênero literário rico em apresentar os sentimentos humanos, sejam estes desejos, sonhos, amores, conflitos ou mazelas. Uma característica essencial da Poesia é sua capacidade de capturar a atenção do leitor e despertar sua sensibilidade em relaçáo aos temas contidos nos versos.

Num trabalho interdisciplinar, nas aulas de Geografia na Educaçáo Básica, o poema supracitado, por exemplo, pode ser um ponto de partida para estudos de temas como paisagens urbanas, desigualdade social, segregaçáo espacial e cidadania. É possível que sua leitura e interpretação estimule a percepção dos alunos em relação às paisagens e oportunize o desenvolvimento de um olhar crítico sobre a realidade. Para isso, é importante que os professores explorem a linguagem literária da construção poética.

No poema de Manuel Bandeira, essa linguagem é sublime em demonstrar um uso expressivo e rítmico das palavras. Note-se, por exemplo, que o olhar do "eu lírico" é de admiraçáo, de espanto em relaçáo à cena observada. $\mathrm{O}$ poeta, pela maneira com que constrói os versos, atribuindo ao homem um comportamento animal, consegue envolver o leitor no seu próprio sentimento cabuloso: fala de um bicho, um bicho qualquer/ descreve as atitudes grotescas desse bicho à procura de comida/ faz suspense com a identidade do bicho/ revela a identidade humana do bicho, numa espécie de clímax do poema.

Outras poesias de dimensão social, com variadas características de linguagem, podem adquirir relevância nos estudos da Geografia Escolar. Haesbaert (2002) é um dos geógrafos que viram na Poesia um lugar de temáticas geográficas. Em Território, Poesia e Identidade, esse autor escreve sobre a relaçáo da Geografia com a Poesia, destaca aspectos da visão poética e do fazer poético e defende que a Poesia é guardiã de territórios e identidades que a dinâmica espacial globalizante desenraiza.

Os escritos de muitos poetas contribuíram e contribuem para o imaginário das pessoas em relaçáo ao Brasil. Por exemplo, nos poemas em que Cora Coralina explicita as paisagens de Goiás, Carlos Drummond de Andrade mostra os costumes das gentes de Minas Gerais ou, ainda, Patativa do Assaré narra as dificuldades do sertáo do Nordeste, o Brasil é manifesto em 
suas identidades regionais, em seus valores culturais, seus problemas sociais, sua natureza tropical.

O mundo vivido encontrado na Poesia também se faz presente nas Crônicas do Cotidiano. Nesta modalidade de Crônicas, o cronista, na condiçáo de expectador dos acontecimentos diários, emite opiniôes em relaçáo a estes, ao mesmo tempo que oferece elementos importantes para a reflexáo sobre a realidade.

Sousa e Chaveiro (2008) realizaram um estudo geográfico a partir do livro de Crônicas Viver é Devagar, de Brasigóis Felício. Nessas Crônicas, os autores buscaram representaçóes da cidade de Goiânia que pudessem levar a um entendimento do processo histórico-social dessa cidade. Para isso, serviram-se das categorias geográficas lugar, paisagem e espaço urbano, associando-as à categoria tempo e à de representação social.

$\mathrm{Na}$ sala de aula, a dimensão social das Crônicas permite tecer relaçóes importantes com conteúdos geográficos. Muitos cronistas brasileiros da estirpe de Luís Fernando Veríssimo, Brasigóis Felício e Fernando Sabino, por exemplo, demonstram ser exímios observadores de gentes e de paisagens. Suas crônicas sáo portadoras de conteúdos sociais e espaciais.

Assim como as Poesias e as Crônicas, Romances e Contos sáo gêneros literários ricos em abrigar conceitos e categorias geográficas. Trata-se de narrativas nas quais o enredo, as personagens, o espaço onde a trama de desenrola e o tempo em que ela ocorre proporcionam uma visáo ampla de uma dada realidade espacial.

Os Romances, segundo Almeida (1985), caracterizam-se por ser tramas mais longas e mais complexas, as quais permitem uma inserçâo gradativa do leitor nas realidades narradas. Os Contos, na explicaçáo de Gotlib (2001), têm como uma de suas principais características a brevidade - que permite uma leitura ininterrupta - e a capacidade de condensar os fatos mais significativos da realidade narrada.

Nos dois gêneros, é possível realizar leituras importantes das geografias dos lugares. Graciliano Ramos, Euclides da Cunha, Carmo Bernardes e Bernardo Élis sáo exemplos de autores que nos seus Romances e Contos revelaram aspectos essenciais do Brasil, sobretudo do universo sertanejo, do modo de ser sertanejo. Suas obras permitem, por exemplo, conhecer o passado cultural do Brasil - a vivência rural, a vivência urbana nas pequenas e médias cidades - e tecer relaçóes importantes com a ruralidade e a urbanidade atuais. 
Isso é possível porque a realidade espacial e temporal, enredada nas narrativas, é perpassada pelas características do seu período histórico. $\mathrm{Ou}$ seja, é de uma determinada formação socioespacial que os autores retiram os elementos concretos para compor as tramas. É nesse sentido que as narrativas demonstram certa fidelidade à descriçáo das paisagens dos lugares e das suas características sociais, culturais, naturais, políticas e econômicas. Tais características sáo realçadas pela voz narrativa e pelos conflitos vividos pelas personagens. Está aí a matéria-prima para auxiliar a interpretaçáo geográfica de períodos específicos da história.

Olanda e Almeida (2007), Braga e Almeida (2009) realizaram trabalhos nesse sentido. Elas estudaram, respectivamente, a representaçáo das paisagens culturais em dois romances de Carmo Bernardes - Memórias do Vento e Jurubatuba - e a ressignificaçáo da identidade sertaneja em Goiás a partir da leitura geográfica dos livros de contos Ermos e Gerais, Caminhos e Descaminhos e Veranico de Janeiro, de Bernardo Élis. Os estudos realizados por essas autoras sugerem que os gêneros Romance e Contos sáo apropriados a estudos regionais nos quais é possível aprofundar o olhar sobre a relaçáo dos sujeitos com o espaço.

Nessa perspectiva, as categorias lugar, território, natureza, regiāo e paisagem têm a possibilidade de ser refletidas de forma mais complexa, já que as narrativas oferecem elementos que justificam essa complexidade. Os professores podem aproveitar as características da linguagem literária presentes em Romances e Contos - como, por exemplo, a metáfora, a conotaçáo, os discursos diretos, a fala coloquial das personagens e o uso expressivo das palavras - para atingir os objetivos do ensino e da aprendizagem da Geografia Escolar.

\section{Conclusáo}

Buscamos, por meio deste artigo, suscitar reflexóes sobre os elos existentes entre a Geografia e a Literatura, bem como incentivar a interdisciplinaridade das duas linguagens no processo de ensino e aprendizagem da Geografia Escolar. Diante do exposto, foi possível perceber que os gêneros literários - Poesia, Crônica, Romance e Conto - oferecem um repertório de leituras geográficas e que o dialogismo entre o real e o imaginário é capaz de potencializar o olhar geográfico sobre a realidade. A concepçáo de interdisciplinaridade implícita no artigo é aquela que entende o trabalho interdisci- 
plinar como uma forma de conduzir os alunos a uma visão menos fragmentada do mundo (JAPYASSU, 1976; FAZENDA, 1992; MORIN, 2005).

Há várias metodologias para se abordar Geografia e Literatura e vários conteúdos a ser trabalhados de modo interdisciplinar. Em um projeto interdisciplinar - que pode ser orientado pelos professores de Geografia ou, ainda, por estes professores em conjunto com os de Literatura -, é importante que haja a clareza, conforme explica Cavalcanti (2005), de que os métodos e os conteúdos geográficos estáo a serviço dos objetivos a ser alcançados nas atividades escolares.

Ou seja, é necessário que os professores tenham consciência da relevância das temáticas de Geografia, bem como da importância da comunicação da Geografia com a Literatura nos ensinos Fundamental e Médio. Neste sentido, cabe aos professores, mediante as especificidades de seu contexto escolar e da sua relaçáo com os alunos, criar, planejar e experienciar as atividades interdisciplinares consideradas mais apropriadas à Educação Básica.

O diálogo da Geografia com a Literatura oferece uma oportunidade para os professores de Geografia ampliarem suas práticas de ensino, que desempenham um papel fundamental na formaçáo dos alunos. Elas sáo responsáveis, por exemplo, pelas seguintes atividades: criar situaçóes adequadas de aprendizagem; propiciar a construção e a apropriação de conhecimentos; direcionar e redirecionar a dinâmica das aulas; e, ainda, favorecer as dimensôes conceitual, procedimental e atitudinal do saber geográfico.

Esperamos que as reflexóes e proposiçóes deste artigo colaborem para a diversificação e o fortalecimento do fazer pedagógico dos professores de Geografia de diferentes ambientes escolares.

\section{Referências}

ALMEIDA, N. Alves. Estudos sobre quatro regionalistas. 2. ed. Goiânia: Ed. UFG, 1985.

BOSI, A. (Org.). Cultura brasileira: temas e situaçóes. 3 ed. Sáo Paulo: Ática, 1999.

BOSI, A.. Reflexóes sobre a arte. Sáo Paulo: Ática, 2004.

BANDEIRA, Manuel. Estrela da vida inteira. 20. ed. Rio de Janeiro: Nova Fronteira, 1993. 
BARBOSA, J. P. Caderno dois. Goiânia: Kelps, 2011.

BRAGA, H. C. A identidade sertaneja em Goiás: um estudo a partir dos elos entre a Geografia e a Literatura de Bernardo Élis. 2010. Dissertação (Mestrado em Geografia) - Universidade Federal de Goiás, Goiânia, 2010.

CANDIDO, A. Literatura e sociedade. 4 ed. Sáo Paulo: Nacional, 1975. CASTROGIOVANNI, Antonio Carlos (Org.). Ensino de Geografia práticas e textualizaçóes no cotidiano. 5 ed. Porto Alegre: Mediação, 2006.

CLAVAL, P. Campos e perspectivas da Geografia Cultural. In: CORRÊA, R. L.; ROSENDAHL, Z. (Org.). Geografia Cultural: um século. Rio de Janeiro: Ed. UERJ, 2002.

CORREA, R. L. ROSENDAHL, Z. (Org.). Literatura, música e espaço. Rio de Janeiro: Ed. UERJ, 2007.

COSGROVE, D. E. Em direção a uma geografia cultural radical: problemas da teoria. In: CORREA, R. L.; ROSENDAHL, Z. (Org.). Introdução à Geografia Cultural. Rio de Janeiro: Bertrand Brasil, 2003. p. 103-134.

COSGROVE, D. E. A geografia está em toda parte: cultura e simbolismo nas paisagens humanas. In: CORREA, R. L.; ROSENDDAHL, Z. (Org.) Paisagem, tempo e cultura. Rio de Janeiro: Ed. UERJ, 1998. p. 92-121.

CUCHE, D. A noção de cultura nas Ciências Sociais. Tradução de Viviane Ribeiro. 2 ed. Bauru: Ed. USC, 2002.

DURAND, Gilbert. A imaginação simbólica. São Paulo: Cultrix, 1993.

ECO, U. Lector in fabula: a cooperaçáo interpretativa nos textos narrativos. Sáo Paulo: Perspectiva, 1986.

FAZENDA. Ivani. Integração e interdisciplinaridade no ensino brasileiro: efetividade ou ideologia? Sáo Paulo: Loyola, 1992.

GOMES, A. L. et al. (Org.). Entre textos: ensaios sobre literatura, cinema, semiótica, educaçáo e música. Sáo Paulo: Antiqua, 2004.

GONÇALVES, Carlos Walter Porto. A invenção de novas geografias: a natureza e o homem em novos paradigmas. In: SANTOS, Milton et al. Território, territórios: ensaios sobre ordenamento territorial. 3. ed. Rio de Janeiro: Lamparina, 2007. p. 375-379. 
GOTLIB, N. B. Teoria do conto. Sáo Paulo: Ática, 2001.

GUILLEN, I. C. M. O sertáo e a identidade nacional em Capistrano de Abreu. In: BURITY, J. A. (Org.). Cultura e identidade: perspectivas interdisciplinares. Rio de Janeiro: DP\&A, 2002. p.105-124.

HAESBAERT, R. Território, poesia e identidade. Espaço e Cultura, UERJ, Rio de Janeiro, n. 3, p. 20-32, 1997.

JAPIASSU, H. Interdisciplinaridade e patologia do saber. Rio de Janeiro: Imago, 1976.

JODELET, D. As representaçóes sociais: um domínio em expansão. Tradução de Lílian Ulup. Rio de Janeiro: Ed. UERJ, 2001.

KAERCHER, Nestor André. Desafios e utopias no ensino de Geografia. 3. ed. Santa Cruz do Sul: Ed. Unisc, 2001.

KOZEL, S.; MENDONÇA, F. (Org.). Elementos de epistemologia da Geografia. Paraná: UFPR, 2004.

KOZEL, S.; MENDONÇA, F. (Org.). Da percepção e cognição à representação. Sáo Paulo: Neer, 2007.

LAJOLO, M. O que é literatura. São Paulo: Brasiliense, 1981.

MAFFESOLI, M. O imaginário é uma realidade. Famecos, Porto Alegre, n. 15, p. 74-82, ago. 2001.

MARANDOLA JR., Eduardo; GRATÁO, Lúcia Helena Batista (Org.). Geografia e Literatura: ensaios sobre geograficidade, poética e imaginação. Londrina: Ed. UEL, 2010.

MONTEIRO, C. A. F. O mapa e a trama: ensaios sobre o conteúdo geográfico em criaçóes romanescas. Florianópolis: Ed. UFSC, 2002.

MORIN, Edgar. Os sete saberes necessários à educação do futuro. São Paulo: Cortez, 2005.

OLANDA, D. A. M. As representaçóes de paisagens culturais do espaço goiano em obras carmobernadianas: Memórias do Vento e Jurubatuba. 2006. Dissertação (Mestrado em Geografia) - Universidade Federal de Goiás, Goiânia, 2006. 
ORTEGA Y GASSET. A desumanização da arte. São Paulo: Cortez, 1999. PONTUSCHKA, Nídia N.; OLIVEIRA, Ariovaldo U. (Org.). Geografia em perspectiva: ensino e pesquisa. São Paulo: Contexto, 2009.

SANTOS, M. Metamorfose do espaço habitado. Sáo Paulo: Hucitec, 1997.

SANTOS, Rogério Santana. O triunfo do conto: em Hugo de Carvalho Ramos e Bernardo Élis. 2004. Tese (Doutorado em Literatura Brasileira) - Faculdade de Filosofia, Letras e Ciências Humanas, Universidade de São Paulo, São Paulo, 2004.

STRAFORINI, Rafael. Ensinar Geografia: o desafio da totalidade-mundo nas séries iniciais. Sáo Paulo: Annablume, 2004.

WANDERLEY, V. M. Geografia e poesia do sertâo nordestino: uma revisitaçáo às trilhas romanescas de Ariano Suassuna. In: DINIZ, J. F et al. (Org.). Capitulos de Geografia nordestina. Aracaju: NPGEO/UFS, 1998.

Recebido em: 29 mar. 2016.

Aceito em: 10 abr. 2016. 